\title{
Relationships Between Hydrodynamics and Rheology of Flocculating Yeast Suspensions in a High-Cell-Density Airlift Bioreactor
}

\author{
Jaroslav Klein, ${ }^{1}$ João Maia, ${ }^{2}$ António A. Vicente, ${ }^{1}$ Lucília Domingues, $^{1}$ \\ José A. Teixeira, ${ }^{1}$ Martin Juraščík ${ }^{3}$ \\ ${ }^{1}$ Centro de Engenharia Biológica, Universidade do Minho, Campus de Gualtar, \\ 4710-057 Braga, Portugal; telephone: + 351-253-604406; \\ fax: + 351-253-678986; e-mail: jateixeira@deb.uminho.pt \\ ${ }^{2}$ IPC - Institute for Polymer Composites, Department of Polymer Engineering, \\ University of Minho, Campus de Azurém, 4800 - 058 Guimarães, Portugal \\ ${ }^{3}$ Department of Chemical \& Biochemical Engineering, Faculty of Chemical \& \\ Food Technology, Slovak University of Technology, Radlinského 9, 81237 \\ Bratislava, Slovakia
}

Received 7 May 2004; accepted 9 September 2004

Published online 5 January 2005 in Wiley InterScience (www.interscience.wiley.com). DOI: 10.1002/bit.20335

\begin{abstract}
In this article a hydrodynamic and rheological analysis of a continuous airlift bioreactor with high-celldensity system is presented. A highly flocculating recombinant strain of Sacharomyces cerevisiae containing genes for lactose transport (lactose permease) and hydrolysis ( $\beta$-galactosidase) was exploited to ferment lactose from cheese whey to ethanol. The magnetic particle-tracer method was used to assess the effect of operational conditions (air-flow rate, biomass concentration) on hydrodynamic behavior of an airlift bioreactor during the fermentation process. Measurements of liquid circulation velocity showed the existence of a critical value of biomass concentration at which a dramatic deceleration of net liquid flow appeared with increasing biomass quantity. Rheological analysis revealed exponential increase of viscosity of the yeast floc suspension at the same biomass concentration of about $73 \mathrm{~g} / \mathrm{dm}^{3}$ corresponding to $42.8 \% \mathrm{v} / \mathrm{v}$ of solid fraction. These facts have a particular importance for the successful processing of a high-celldensity airlift bioreactor as only a circulated flow regime will be favorable to keep the solid particles in suspension state and evenly distributed throughout the bioreactor. (C) 2004 Wiley Periodicals, Inc.
\end{abstract}

Keywords: continuous airlift bioreactor; hydrodynamics; biomass; high-cell-density system; flocculation; viscosity

\section{INTRODUCTION}

In recent years, there has been a growing interest in bioreactors utilizing immobilized enzymes and cells to improve the bioprocess productivity. In fact, there are many specific advantages of immobilized systems in comparison with the more conventional systems, in which the bio-

Correspondence to: José A. Teixeira

Contract grant sponsor: Marie Curie Fellowship of the European Community Programme

Contract grant number: HPMF-CT-2002-01643 agents are suspended freely (cells) or dissolved in a bulk aqueous medium (enzymes) (Domingues et al., 2000). In addition to conventional immobilization techniques, the use of flocculating microorganisms is very attractive since there is no need of mechanical devices or supports (Kida et al. 1989; Roca et al. 1995). This is a great advantage since it is well known that the support represents a major cost in immobilization procedures.

In practice, a high-cell-density system (HCDS) usually represents a three-phase (gas-liquid-solid) dispersion operating with a liquid phase in continuous mode. Due to the very high solid loading (up to $50-60 \% \mathrm{v} / \mathrm{v}$ ) usually required (Vicente et al., 2001), maintaining the solid particles suspended and evenly distributed is a major task for successful bioreactor operation. For these systems, a continuous airlift bioreactor (ALR) with an enlarged head zone seems to be a very attractive option due to a high retention of the solid phase and also due to the advantageous combination of sufficient mixing and low shear stress (Freitas and Teixeira, 1998; Vicente and Teixeira, 1995). In airlift bioreactors the maintenance of a solid phase in movement is possible due to the net circulation flow established between the riser and downcomer sections. Basically, three flow regimes in three-phase airlift reactors were defined (Fan et al., 1984): the packed bed regime (no suspension of particles and no liquid circulation), the fluidized bed regime (with particle suspension exclusively in the riser and non-zero liquid circulation) and the circulated bed regime (with the solid phase distributed throughout the reactor). Airlift reactors with high crosssectional area ratio $A_{D} / A_{R}$ and with high loading of low density solid particles (typical features of a HCDS) favor the direct change from packed to circulation bed mode (Petrovic et al., 1993). Knowing the magnitude of the circulation velocity during the bioprocess can provide 
prompt and useful information about the variations of partial processes (affected by hydrodynamics) in individual parts of the reactor. Those processes can be the three-phase flow regime (Klein et al., 2003b), the RTD of bio-particles and the mixing intensity, the mass transfer or the shear stress provoked on bio-particles having an effect on their physical and colloidal properties.

For high-cell-density systems, the circulated flow regime is highly desirable providing high gas hold-up, high contacting efficiency between all phases, and an even solid distribution throughout the ALR (Fan et al., 1984). A collapse of net circulation (bioreactor stalling) would have very negative effects on the overall functionality and productivity of the fermentation. This justifies the need to avoid the bioreactor stalling by the application of an optimal bioreactor design and suitable operating conditions (circulation velocity, gas-flow rate, biomass concentration).

One of the attractive possibilities for the utilization of a high-cell-density system is alcoholic continuous fermentation of lactose from cheese whey using flocculating yeast. Cheese whey, as a byproduct of the dairy industry, represents a significant environmental problem due to very high values of biochemical oxygen demand (BOD) and chemical oxygen demand (COD). For this purpose, a flocculating recombinant strain of Sacharomyces cerevisae containing lactose metabolism genes coding for lactose permease and $\beta$-galactosidase was developed, enabling the hydrolysis of lactose to galactose and glucose, followed by sugar conversion into ethanol (Domingues et al., 1999). In continuous operation, an ethanol productivity of $11 \mathrm{~g} \mathrm{dm}^{-3}$ $\mathrm{h}^{-1}$ was reached at a dilution rate of $0.55 \mathrm{~h}^{-1}$, being several times higher than in conventional batch or continuous systems (Domingues et al., 2001).

Our main goal in this work was to study the hydrodynamics of a continuous airlift bioreactor during fermentation of lactose to ethanol using an highly flocculating yeast. The magnetic particle-tracer method was used for the assessment of the effect of operating conditions (air-flow rate, biomass concentration) on the hydrodynamics of the airlift bioreactor as a whole and also on its individual sections. In view of the very strong variations observed in circulation velocity during the fermentation process, a rheological analysis of the floc suspensions at different concentrations was also performed and the results correlated with those from the hydrodynamic study.

\section{MATERIALS AND METHODS}

\section{Yeast Strain and Conditions of Cultivation}

A recombinant Saccharomyces cerevisiae NCYC869-A3/ T1 flocculent strain expressing the LAC4 (coding for $\beta$-galactosidase) and LAC12 (coding for lactose permease) genes of Kluyveromyces lactis was used. The construction of the recombinant strain is described in detail by Domingues et al. (1999).
The composition of the semi synthetic medium used for cultivation and fermentation was as follows (in $\mathrm{g} / \mathrm{dm}^{3}$ ): Lactose, 50; $\mathrm{KH}_{2} \mathrm{PO}_{4}, 5 ;\left(\mathrm{NH}_{4}\right)_{2} \mathrm{SO}_{4}, 2 ; \mathrm{MgSO}_{4} \cdot 7 \mathrm{H}_{2} \mathrm{O}, 0.4$ and yeast extract, 1 . Foam level was controlled by adding Antifoam 204 (SIGMA, Germany). The inoculum was cultivated first in $100 \mathrm{~mL}$ of medium in a 250-mL Erlenmeyer flask for $24 \mathrm{~h}$ and then in $1 \mathrm{~L}$ of medium in a 2-L Erlenmeyer flask for further $24 \mathrm{~h}$ in a rotary shaker at $150 \mathrm{rpm}$ and $30^{\circ} \mathrm{C}$. Finally, $1 \mathrm{~L}$ of inoculum (with $\approx 2.0 \mathrm{~g} / \mathrm{dm}^{3}$ of dry biomass concentration) was passed aseptically into a 6-L airlift reactor and kept in batch operation under aeration $(0.1 \mathrm{vvm})$ until $90 \%$ of the lactose was consumed. The temperature was maintained at $30^{\circ} \mathrm{C}$ and the $\mathrm{pH}$ was set at 4.0.

\section{Bioreactor and Operational Conditions}

The bioreactor used in this work was a 6-L internal loop airlift with an enlarged degassing zone, made of Plexiglas. The head zone had the shape of a reversed cut cone with a cylindrical overhead. The conical section formed a $50^{\circ}$ angle with the main body of the reactor. The reactor drawing with all dimensions is presented in Figure 1. The diameter of the draft tube was $42 / 50 \mathrm{~mm}$, and the $A_{D} / A_{R}$ ratio was 1.36 . The air injection was made via a perforated plate of $16 \mathrm{~mm}$ diameter, with 10 holes of $0.5 \mathrm{~mm}$ diameter each, placed $25 \mathrm{~mm}$ below the bottom of the draft tube. The washout of biomass was minimized by means of an efficient sedimentation barrier placed around the outlet.

The temperature inside the reactor was maintained at $30 \pm 0.5^{\circ} \mathrm{C}$ by means of a jacket where water at a controlled temperature was circulated. The $\mathrm{pH}$ control was performed by the automatic addition of ammonia solution being the set point fixed at $4 \pm 0.1$. An efficient condenser was located at the top of the bioreactor, in the line of outlet gas. The reactor was operated at various dilution rates from 0.08 to $0.4 \mathrm{~h}^{-1}$ and at aeration rates from 0.63 to $2.76 \mathrm{~L} / \mathrm{min}^{-1}$ (referred to $20^{\circ} \mathrm{C}$ and $1 \mathrm{~atm}$ ), corresponding to values of 0.1 to $0.45 \mathrm{vvm}$ (normal volume of air per volume of reactor per minute) The air-flow rates were controlled by a rotameter and filtered by a microbiological filter (ZANDER, Germany).

\section{Off-Line Analysis Methods}

\section{Biomass Concentration}

Gravimetry was used to monitor the dry cell weight concentration. A sample of approximately $15 \mathrm{~cm}^{3}$ of biomass suspension was taken through the sample port in the center point of the downcomer and then filtered through $0.45 \mu \mathrm{m}$ filter paper (PALL Corp., USA). The biomass cake obtained was dried at $105^{\circ} \mathrm{C}$ until constant weight. It was shown in a previous work (Klein et al., 2003a) an even distribution in both riser and downcomer sections for suspensions of low-density particles (e.g. alginate beads, yeast 


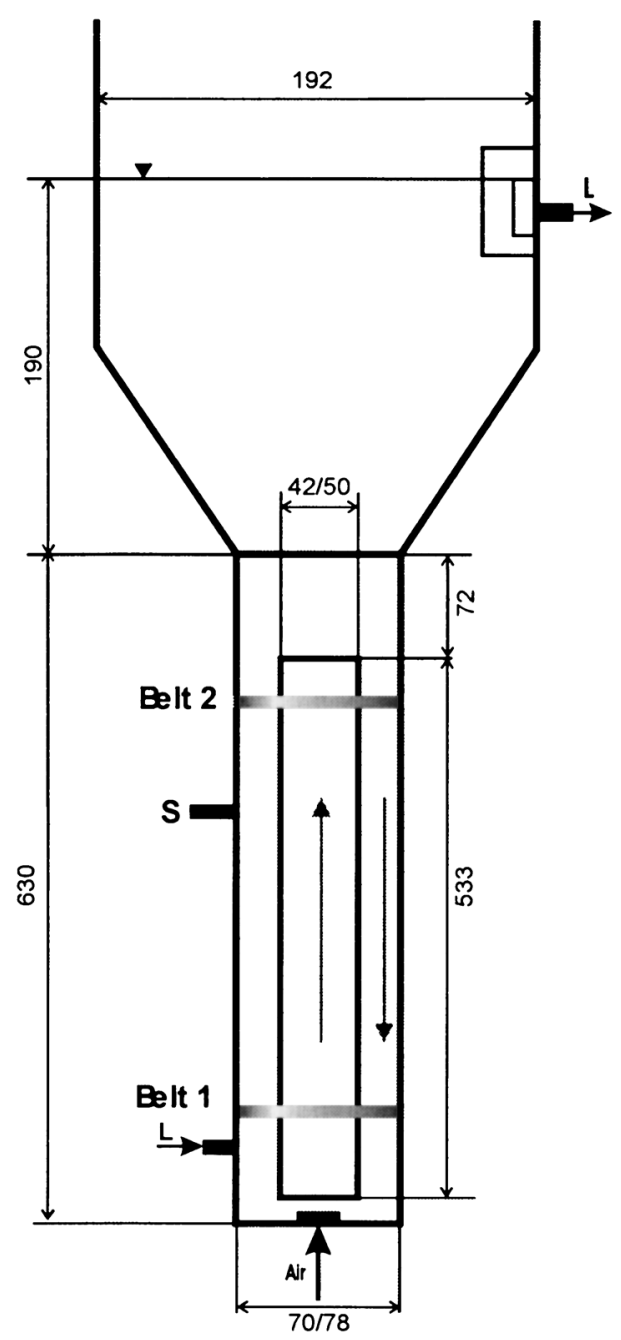

Figure 1. Scheme of a $6 \mathrm{dm}^{3}$ continuous airlift bioreactor. Symbols: Ssample port, $\mathrm{L}-$ feed and outlet. Belts 1 and 2 indicate the position of the measuring coils for liquid velocity measurement by the magnetic tracer method. All dimensions are in $\mathrm{mm}$.

flocs). Thus, the biomass concentration measured in the downcomer was used in the hydrodynamic analysis of the ALR as a representative value of the total biomass. Since the net circulation flow takes place only in the main vertical reactor sections, the biomass present in the head enlarged zone was not considered for the total biomass concentration, $c_{X}$.

\section{Density of Biomass Suspension and Liquid Phase}

The density of biomass suspension and liquid phase was determined by pycnometry using a $100 \mathrm{~cm}^{3}$ stopper with capillary at a temperature equal to that in the bioreactor $\left(30^{\circ} \mathrm{C}\right)$. A linear dependence was found between the yeast suspension and dry biomass concentration from five measurements and for four different values of biomass concentration:

$$
\rho_{F L}\left(k g / m^{3}\right)=(1000.43 \pm 0.98)+(0.246 \pm 0.018) c_{X}
$$

The suspension density was then used for the calculation of the effective settling velocity of the tagged particle necessary for determination of the liquid velocity.

\section{Density of Yeast Flocs}

Floc density was determined measuring the weight and volume of the flocs. The biomass suspension was washed 4 times with distilled water before inserting into a $1000 \pm$ $0.4 \mathrm{~mL}$ volumetric flask. The biomass was weighted in the flask and the flask was then filled with a known volume of distilled water at a constant temperature. The floc density $\left(\rho_{S}\right)$ was calculated from the known volume and weight of flocs. $\rho_{S}$ showed to be constant during the whole fermentation, with an average value of $1066.37 \pm 2.18 \mathrm{~kg} / \mathrm{m}^{3}$ (determined from five measurements).

\section{Total Solid Hold-Up}

The volumetric fraction of flocs, $\varepsilon_{s}$, can be determined using the following equation adapted from the work of Vicente et al. (1999):

$$
\varepsilon_{S}=\frac{f c_{x}}{\rho_{S}-\varepsilon_{p} \rho_{L}}
$$

Here, $f$ is the ratio between the total weight of a cell and its dry weight, $c_{x}$ is the dry biomass concentration, $\varepsilon_{p}$ is the floc porosity and $\rho_{S}$ and $\rho_{L}$ are the densities of flocs and liquid phase, respectively.

The factor $f$ was considered to be approximately 10/3, corresponding to about $70 \%$ of water in the cells (Alberts et al., 1994) and $\varepsilon_{p}$ was considered to be 0.50 (Teixeira and Mota, 1990).

\section{Hydrodynamic Measurements}

A magnetic tracer method (Klein et al., 2000) was used to determine the liquid velocity in the airlift reactor. The method makes use of the principle of a magnetic metal locator and a flow-following technique. Two inductive coils were fixed around the column in a mutual vertical distance of $441 \mathrm{~mm}$ to detect the transition of the magnetic tracer particle (see Fig. 1). The density of the tagging particle with a diameter of $5.7 \mathrm{~mm}$ was adjusted to be very close to that of the floc suspension, resulting in a low settling velocity (up to $2 \mathrm{~cm} / \mathrm{s}$ ). The measuring technique allows liquid velocities, circulation velocity, and residence times of the tagging particle to be determined in the airlift reactor, both in its individual sections and as average values for the whole reactor. The overall circulation velocity $\left(V_{L C}\right)$ was determined as the average velocity in the two main reactor sections (riser and down comer) assuming that the tagged particle does not reside in the head separator zone. The technique was already successfully tested to measure the particle and liquid velocities in an internal-loop airlift bioreactor with both two- and three-phase model systems 
(water-air and water-air-alginate beads) (Klein et al., 2003a) as well as during gluconic acid production (Dolgos et al., 2001).

\section{Rheological Measurements}

The viscosity of the floc suspension at different biomass concentrations was measured by means of a Modular Compact Rheometer Physica, MCR-300 (Paar-Physica). Controlled shear-stress measurements were done using parallel-plate geometry of $25 \mathrm{~mm}$ diameter, with a gap of $2 \mathrm{~mm}$, at a constant temperature of $30^{\circ} \mathrm{C}$. The applied shear stress ranged from 0.1 to $200 \mathrm{~Pa}$. Before any measurements were carried out, a sample with the desired concentration was first prepared and homogenized and left for a few minutes for the sample temperature to stabilize. The rheological measurements were carried out in triplicate for each value of biomass concentration, using fresh samples.

\section{RESULTS AND DISCUSSION}

\section{Hydrodynamics in the Airlift Bioreactor}

The particle with high relative magnetic permeability was aseptically inserted into the bioreactor at the beginning of the fermentation, thus becoming available for velocity measurements at any process time. As the biomass accumulated during the whole fermentation, hydrodynamic measurements were carried out to obtain information on how circulation velocity varies with biomass concentration. Moreover, short-term changes of air-flow rate were applied to determine its effect on bioreactor hydrodynamics. The effect of superficial gas velocity, $U_{G c}$, on overall circulation velocity, $V_{L C}$, at different biomass concentrations is shown in Figure 2. The circulation velocity increased with

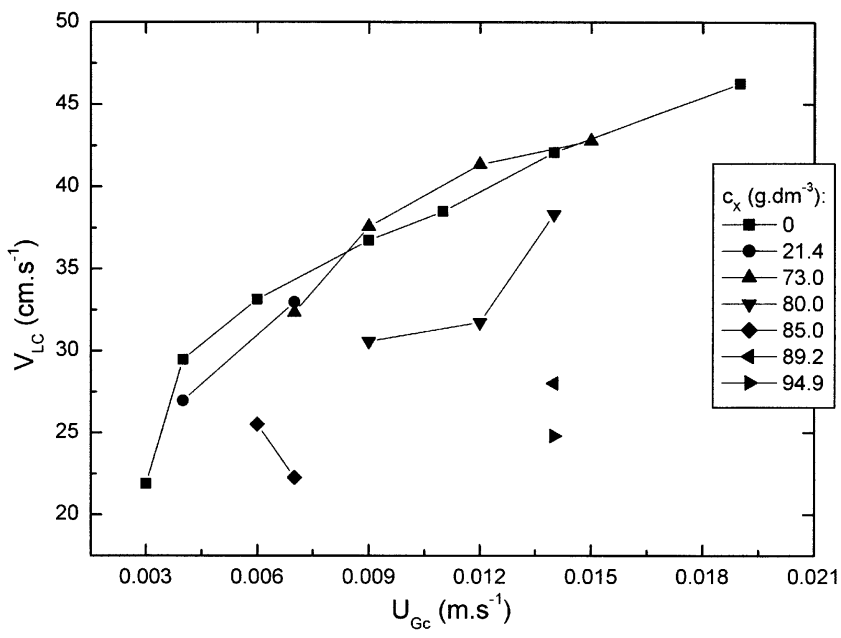

Figure 2. Effect of superficial gas velocity, $U_{G c}$, on overall circulation velocity, $V_{L C}$, at different biomass concentrations in the bioreactor, $c_{X}$. Tap water was used for measurements at zero $c_{X}$. The range of $U_{G c}$ applied corresponds to the range of air flow rates $Q_{G}$ from 0.1 to $0.45 \mathrm{vvm}$.
$U_{G c}$ following a common logarithmic curve (Chisti, 1989). It is evident from the graph that the increase of gas-flow rate improves the net circulation flow up to a biomass concentration of $\approx 80 \mathrm{~g} / \mathrm{dm}^{3}$. Unfortunately, few experimental data were available at higher $c_{X}$ concentrations; therefore, any further conclusions on the effect of $U_{G c}$ for those values of $c_{X}$ would be only speculative.

The effect of biomass concentration on hydrodynamics during the fermentation process is shown in Figure 3. The results revealed that the dependence of the overall circulation velocity on biomass concentration does not present a monotonous behavior for the tested concentration values. Surprisingly, as the biomass accumulates, the velocity $V_{L C}$ remains approximately constant for any of the studied values of air-flow rate. This initial plateau on the velocitybiomass concentration curve at lower $c_{X}$ concentrations was followed by a sudden steep decline indicating a strong degradation of net circulation flow. A dramatic decrease of liquid velocity beyond the critical biomass concentration $c_{X c r i t}$ equal to $73 \mathrm{~g} / \mathrm{dm}^{3}$ (corresponding to $42.8 \% \mathrm{v} / \mathrm{v}$ of solids fraction, see solid vertical line in Fig. 3) was found for all air-flow rates applied (e.g., from 73 to $80 \mathrm{~g} / \mathrm{dm}^{3}$ the $V_{L C}$ decrease was $20 \%$ on average). This breakpoint was found to be a crucial parameter for the operation of a high-cell-density airlift bioreactor, representing the onset of potential appearance of bioreactor stalling (stopping the net circulation).

There was also an attempt to experimentally determine the maximum biomass concentration allowing the operation of the airlift bioreactor in a circulated three-phase flow regime. During the whole fermentation no natural regulation of biomass concentration inside the bioreactor was observed. The system continuously accumulated biomass up to a point where reactor stalling occurred. The biomass started to accumulate at the bottom part of downcomer, finally resulting in the break-up of the net

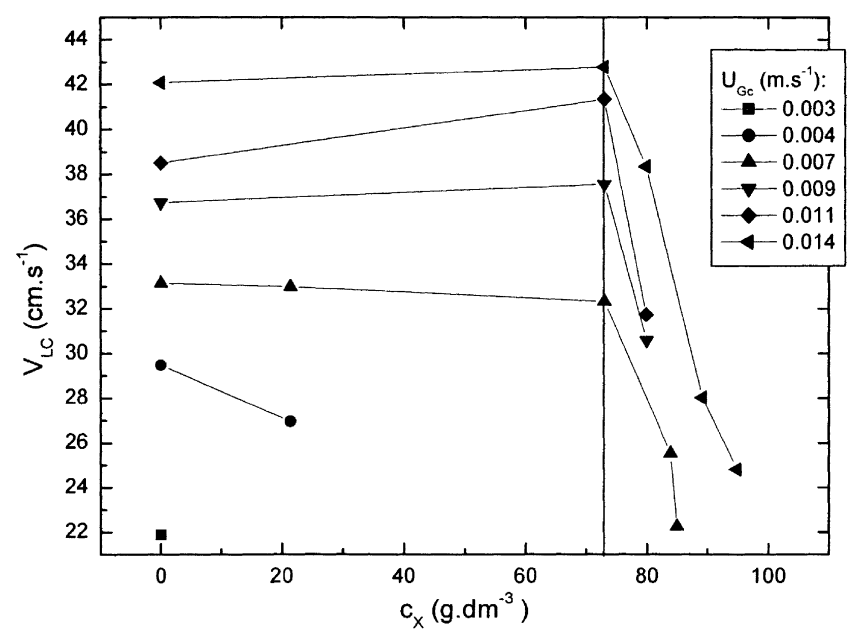

Figure 3. Effect of biomass concentration, $c_{X}$, on overall circulation velocity, $V_{L C}$, at different superficial gas velocity, $U_{G c}$. A solid line marks a critical value of biomass concentration, $c_{X c r i t}$. A range of $U_{G c}$ applied corresponds to the range of air flow rates $Q_{G}$ from 0.1 to $0.45 \mathrm{vvm}$. 
circulation. The maximum concentration of biomass achieved in the bioreactor before stalling occurred $\left(c_{X \max }\right)$ was found to be higher than the critical value previously defined (e.g., at the highest air-flow rate of $0.45 \mathrm{vvm}, c_{X \max }$ was higher than the critical value by $40 \%$ ).

Note another important occurrence observed from the velocity curves in Figure 3: the critical value of biomass concentration was independent of the gas-flow rate. It means that on one hand, an increase of air-flow rate will increase circulation-flow rate, but on the other hand it will not help to increase the critical limit for biomass concentration for which the strong decrease of the circulation velocity can start to be observed.

\section{Rheology of Floc Suspensions}

One of the possible reasons of such sudden decrease in circulation velocity with biomass concentration could be a change of viscosity of the yeast floc suspension. Hence, a rheological analysis of floc suspension in the whole range of biomass concentrations was carried out and an appropriate rheological model was suggested to describe the viscosity curves. The Cross viscosity model provided the best fit for the experimental data once it has the capability of handling Newtonian regions of shear-thinning fluids at low and high shear rates:

$$
\eta_{F L}=\eta_{\infty}+\frac{\eta_{0}-\eta_{\infty}}{\left(1+m \dot{\gamma}^{n}\right)}
$$

Here, $\eta_{F L}$ is the apparent viscosity of the floc suspension, $\eta_{0}$ and $\eta_{\infty}$ are viscosities of Newtonian regions for low and high shear rates, respectively, $\dot{\gamma}$ is the shear rate and $m$ and $n$ are correlation coefficients.

The experimental viscosity curves with the corresponding Cross model fits are depicted in Figure 4. As would be expected, the floc suspensions show a yield stress that increases with biomass concentration. It was not possible to collect enough data at low stresses to accurately determine the yield stress. In the flow region, the behavior of these suspensions can be divided into two different categories. Above a biomass concentration of $59 \mathrm{~g} / \mathrm{dm}^{3}$, the behavior is a typical one with a first Newtonian plateau at low stress, followed by a shear-thinning region and a second Newtonian plateau at very high stresses (in these cases, the Cross model was fit only to the data in the flow region, as can be seen from the Fig. 4). Below a biomass concentration of $59 \mathrm{~g} / \mathrm{dm}^{3}$, the behavior is essentially Newtonian.

Several authors have reported on the viscoelastic behavior of yeast suspensions. Labuza et al. (1970) demonstrated the shear-thinning behavior of baker's yeast (S. cerevisiae) for shear rates in the range of 1 to $100 \mathrm{~s}^{-1}$ and for yeast concentrations above $10.5 \%(\mathrm{w} / \mathrm{w})$ and used the power-law model successfully to fit the data. More recently, Mancini and Moresi (2000) also measured the rheology of baker's yeast using different rheometers in the

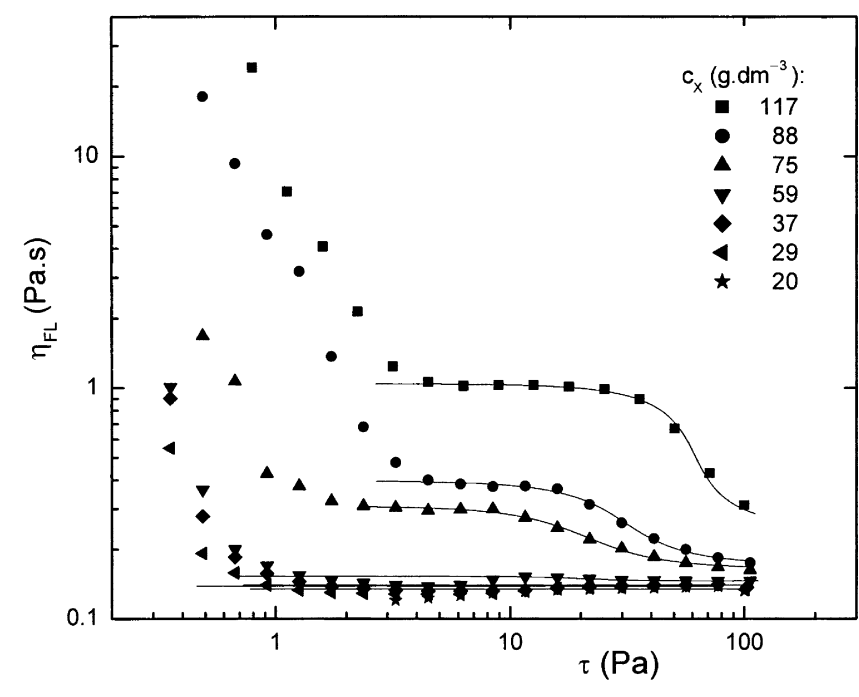

Figure 4. Viscosity curves as a function of shear stress, $\tau$, for different biomass concentrations, $c_{X}$. The lines represent the fittings using the Cross model. All measurements were performed at $30^{\circ} \mathrm{C}$.

concentration range of 25 to $200 \mathrm{~g} / \mathrm{dm}^{3}$. While Haake's rotational viscometer confirmed Labuzás results on the shear-thinning character of the yeast suspension, dynamic stress rheometry revealed a definite Newtonian behavior. They attributed this discrepancy to a lower sensibility of the Haake viscometer in the range of viscosity tested (1.5-12 mPa s). Speers et al. (1993) used a controlled shearrate rheometer with a plate-cone system to measure the viscosity of suspensions of flocculating and nonflocculating strains of S. cerevisiae and $S$. uvarum. They derived a "cell floc" model, which used the Bingham model for the description of viscoplastic flow behavior of cell suspensions:

$$
\eta=\eta_{\infty}+\frac{\tau_{0}}{\dot{\gamma}}
$$

Here $\tau_{0}$ is the yield stress and $\eta_{\infty}$ is the infinite viscosity. The viscosities observed were in the range of 4.6 to $26.9 \mathrm{mPa}$ s for shear rates up to $1000 \mathrm{~s}^{-1}$ and concentration of $2.5 \times 10^{9}$ cells $/ \mathrm{mL}$ (corresponding to $c_{X}$ of about $50 \mathrm{~g} / \mathrm{dm}^{3}$ ), measured at $15^{\circ} \mathrm{C}$. Moreover, they discovered an important fact: the flocculating strains had much higher apparent viscosity and yield stress than nonflocculating ones, which is an indication that the flocculation mechanism of yeast cells has a significant impact on their flow behavior. On the other hand, the shear rate strongly affects floc structures.

It is hardly possible to compare quantitatively the viscosities of yeast suspensions due to its strong relations with the flocculating properties of the yeast strain, as well as to the effect of other factors reported, e.g., in the work of Speers et al. (1992). From all the factors, however, cell concentration and shear rate have the most important effect. It can be concluded from the available literature that yeast suspensions below certain concentrations display a Newtonian behavior, whereas above this limit the flow behavior changes to either shear-thinning or viscoplastic. 


\section{Relation of ALR Hydrodynamics With Rheology}

The assessment of the shear rate in the airlift bioreactor was performed mainly to evaluate its effect on the apparent viscosity of the floc suspension. To do so, the correlation of Henzler and Kauling (1985) was used, which takes into account not only the effect of gas-flow rate but also the fluid properties:

$$
\dot{\gamma}=\left(\frac{\rho_{L} g U_{G}}{\eta_{L}}\right)^{0.5}
$$

From this, it is possible to estimate that the shear rates ranged from 5 to $40 \mathrm{~s}^{-1}$ for all cases studied. Comparing these values with the shear rates reached in rheological measurements, it is possible to conclude that the experiments in the ALR were always performed in a shear rate range for which the suspensions still showed a Newtonian behavior, i.e., the viscosity was still in the first Newtonian plateau.

Figure 5 shows the dependence of zero-shear-rate apparent viscosity of floc suspension on biomass concentration. It clearly demonstrates a dramatic increase of viscosity at $c_{X}$ in the interval of 60 to $75 \mathrm{~g} / \mathrm{dm}^{3}$. Several authors have reported this exponential increase of viscosity of liquidsolid suspensions at higher solid concentrations not only in biological systems (e.g., Speers et al., 1992) but also in a model system composed of liquid and glass beads (e.g., Gandhi et al., 1999).

To determine accurately the point of the strongest increase of viscosity, the intersection of two regression lines for low and high ranges of biomass concentration was calculated and a value of 70.4 was found, which is in a very good agreement with the critical biomass concentration determined from the hydrodynamic measurements (only a $3.7 \%$ difference). This finding explains the strong

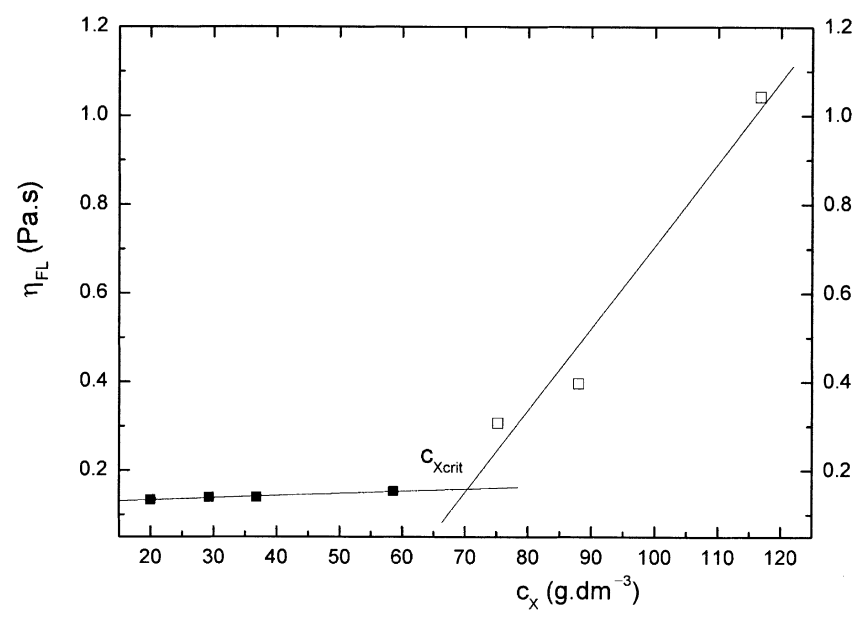

Figure 5. Dependence of viscosity of floc suspension on biomass concentration. $c_{X c r i t}$ is critical value of biomass concentration determined from an intersection of two regression lines.

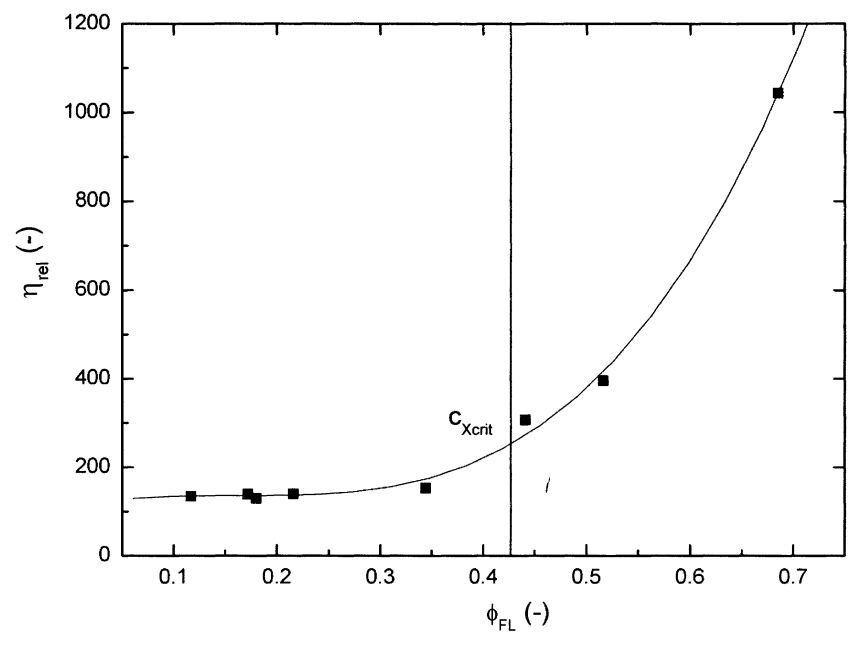

Figure 6. Polynomial regression of relative viscosity of floc suspension, $\eta_{\text {rel }}$, as a function of floc volumetric fraction, $\phi_{F L} \cdot c_{X c r i t}$ is the critical value determined from velocity measurements as the concentration corresponding to the highest decline of $V_{L C}$.

decrease observed in circulation velocity when the biomass concentration increases beyond its critical value. If biomass accumulation continues, the viscosity increases and net circulation slows down, which has a significant negative impact on most of the important phenomena of the bioprocess (mass and heat transfer, mixing, distribution of solid phase, kinetics) and increases the risk of bioreactor stalling. The reasons for this dramatic increase in viscosity above a critical concentration of biomass are not immediately apparent and will be the subject of future work.

Finally, the experimental data were used to describe the dependence of yeast suspension viscosity on biomass concentration. The dependence between the relative viscosity, $\eta_{r e l}$, and the volumetric solid fraction, $\phi_{F L},(\% \mathrm{vol})$ can be satisfactorily correlated by a polynomial regression as follows:

$$
\begin{aligned}
\eta_{\text {rel }}=\eta_{F L} / \eta_{L}= & 109.3+500.5 \phi_{F L}-3096.6 \phi_{F L}^{2} \\
& +6353.2 \phi_{F L}^{3}
\end{aligned}
$$

The regression curve is shown in Figure 6, where $c_{X c r i t}$ is the critical value determined from velocity measurements as the concentration corresponding to the highest decline of $V_{L C}$.

\section{CONCLUSIONS}

The hydrodynamic analysis of a high-cell-density airlift bioreactor during the alcoholic fermentation showed dramatic changes in circulation velocity. Gas-flow rate and especially biomass concentration were found to have the strongest effect on the bioreactor hydrodynamics. Measurements of liquid circulation velocity showed the 
existence of a critical value of biomass concentration at which a dramatic deceleration of net liquid flow appeared with increasing amount of biomass. Rheological analysis revealed strong changes in the viscosity of yeast floc suspensions during fermentation and proved that the breakpoint at the velocity curve corresponds very well to a point of the highest increase of suspension viscosity. From the practical point of the use of an airlift bioreactor as a highcell-density system, this means that the bioreactor should operate below the critical biomass concentration to ensure a safe operation in desirable circulated bed flow regime. The ALR can be operated with higher solid loadings up to a maximal biomass concentration; however, this would have a negative effect on transport phenomena, mixing and solid distribution in the bioreactor. Such information on hydrodynamics in the airlift bioreactor can be used a priori or during the bioprocess to optimize operational parameters to avoid the occurrence of undesirable bioreactor stalling and to maximize the process productivity.

Further experiments with different reactor configurations and on a bigger scale will be performed to generalize these findings in relation to airlift bioreactor hydrodynamics and the rheological behavior of floc suspensions.

\section{NOMENCLATURE}

A cross-sectional area

c concentration

$f$ factor corresponding to about $70 \%$ of water in the cells $\left(\mathrm{m}^{2}\right)$

$m$ regression coefficient

$n$ regression coefficient

$U_{G c} \quad$ superficial gas velocity referred to the riser diameter (averaged at geometrical centre of column)

$V_{L C} \quad$ overall circulation velocity

Greek letters

$\varepsilon_{p} \quad$ floc porosity

$\dot{\gamma}$ shear rate

$\eta \quad$ viscosity

$\eta_{0} \quad$ suspension viscosity at low shear rates

$\eta_{\infty} \quad$ suspension viscosity at high shear rates

$\Phi \quad$ volumetric solid fraction

$\rho_{S} \quad$ density of flocs

$\rho_{F L} \quad$ density of flocs suspension

$\tau \quad$ shear stress

Subscripts

C overall circulation

D downcomer

crit critical value

$F L$ floc suspension

G gas

$L \quad$ liquid

$\max$ maximal value

$R \quad$ riser

rel relative

$X \quad$ biomass dry weight

The authors thank Carla Oliveira for her kind help in preparing the yeast inoculum.

\section{References}

Alberts B, Bray D, Lewis J, Raff M, Roberts K, Watson JD. 1994. Molecular biology of the cell. New York: Garland Publishing, Inc. p 41-43.

Chisti Y. 1989. Airlift bioreactors. London: Elsevier Science Publishers. $345 \mathrm{p}$.

Dolgoš O, Klein J, Blažej M, Markoš J. 2001. Characterisation of hydrodynamics in airlift bio-reactor using the real fermentation broth; ECCE3 2001 June 26-28; Nuremberg, Germany. p 4.

Domingues L, Lima N, Teixeira JA. 2001. Alcohol production from cheese whey permeate using genetically modified flocculent yeast cells. Biotechnol Bioeng 72(5):507-514.

Domingues L, Teixeira JA, Lima N. 1999. Construction of a flocculent Saccharomyces cerevisiae fermenting lactose. Appl Microbiol Biotechnol 51:621-626.

Domingues L, Vicente AA, Lima N, Teixeira JA. 2000. Applications of yeast flocculation in biotechnological processes. Biotechnol Bioproc Eng 5(4):288-305.

Fan L-S, Hwang S-J, Matsuura A. 1984. Hydrodynamic behaviour of a draft tube gas-liquid-solid spouted bed. Chem Eng Sci 39(12): $1677-1688$.

Freitas C, Teixeira JA. 1998. Hydrodynamic studies in an airlift reactor with an enlarged degassing zone. Bioproc Eng 18:267-279.

Gandhi B, Prakash A, Bergougnou MA. 1999. Hydrodynamic behavior of slurry bubble column at high solids concentrations. Powder Technol 103(2):80-94.

Henzler HJ, Kauling J. 1985. Scale-up of mass transfer in highly viscous liquids. Wurzberg, Germany. BHRA, Cranfield. p 303-312.

Kida K, Motozumi Y, Asano S, Nakata T, Slnoda Y. 1989. The effect of aeration on stability of continuous ethanol fermentation by a flocculating yeast. J Ferment Bioeng 68(2):107-111

Klein J, Blažej M, Godó S, Dolgoš O, Markoš J. 2000. Application of a magnetic tracer method for the characterisation of hydrodynamics in internal-loop airlift bioreactors. Chem Papers 54(6b):456-466.

Klein J, Vicente AA, Teixeira JA. 2003a. Hydrodynamic considerations on optimal design of a three-phase airlift bioreactor with high solid loading. J Chem Technol Biotechnol 78:935-944.

Klein J, Vicente AA, Teixeira JT. 2003b. Hydrodynamics of a three phase airlift reactor with en enlarged dual separator-Application to highcell density systems. Can J Chem Eng 81(3-4):433-443.

Labuza TP, Barrera Santos D, Roop RN. 1970. Engineering factors in single-cell protein production. I. Fluid properties and concentration of yeast by evaporation. Biotechnol Bioeng 12:123-134.

Mancini M, Moresi M. 2000. Rheological behaviour of baker's yeast suspensions. J Food Eng 44:225-231.

Petrovic D, Posarac D, Dudukovic A, Skala D. 1993. Minimum fluidization velocity of large particles in a draft tube airlift reactor. Chem Eng Sci 48(14):2663-2667.

Roca E, Ghommidh C, Navarro JM, Lema JM. 1995. Hydraulic model of a gas-lift bioreactor with flocculating yeast. Bioproc Eng 12:269-272.

Speers RA, Durance TD, Tung MA, Tou J. 1993. Colloidal properties of flocculent and nonflocculent brewing yeast suspensions. Biotechnol Progr 9:267-272.

Speers RA, Tung MA, Durance TD, Stewart GG. 1992. Colloidal aspects of yeast flocculation: A review. J Inst Brewing 98:525-531.

Teixeira JA, Mota M. 1990. Experimental assessment of internal diffusion limitations in yeast flocs. Chem Eng 43:B13-B17.

Vicente AA, Dluhý M, Teixeira JA. 1999. Increase of ethanol production in an airlift reactor with a modified draught tube. Can J Chem Eng 77:497-502.

Vicente AA, Mota M, Teixeira JA. 2001. Flocculation bioreactors. In: Cabral JMS, Mota M, Tramper J, editors. Multiphase bioreactor design. London: Taylor \& Francis. p 363-391.

Vicente AA, Teixeira JA. 1995. Hydrodynamic performance of a threephase airlift bioreactor with an enlarged degassing zone. Bioproc Eng 14:17-22. 